\title{
MtDNA MUTATIONS ASSOCIATED WITH MYOCARDIAL INFARCTION
}

\author{
M.A. Sazonova ${ }^{1,2}$, V.V. Sinyov ${ }^{1,2}$, A.I. Ryzhkova ${ }^{1}$, \\ M.D. Sazonova ${ }^{1}$, Z.B. Khasanova ${ }^{2}$, N.A. Doroschuk ${ }^{2}$, \\ N.N. Nikitina ${ }^{2}$, I.A. Sobenin ${ }^{1,2}$, A.N. Orekhov ${ }^{1,3}$
}

${ }^{1}$ Institute of General Pathology and Pathophysiology, Moscow, Russian Federation;
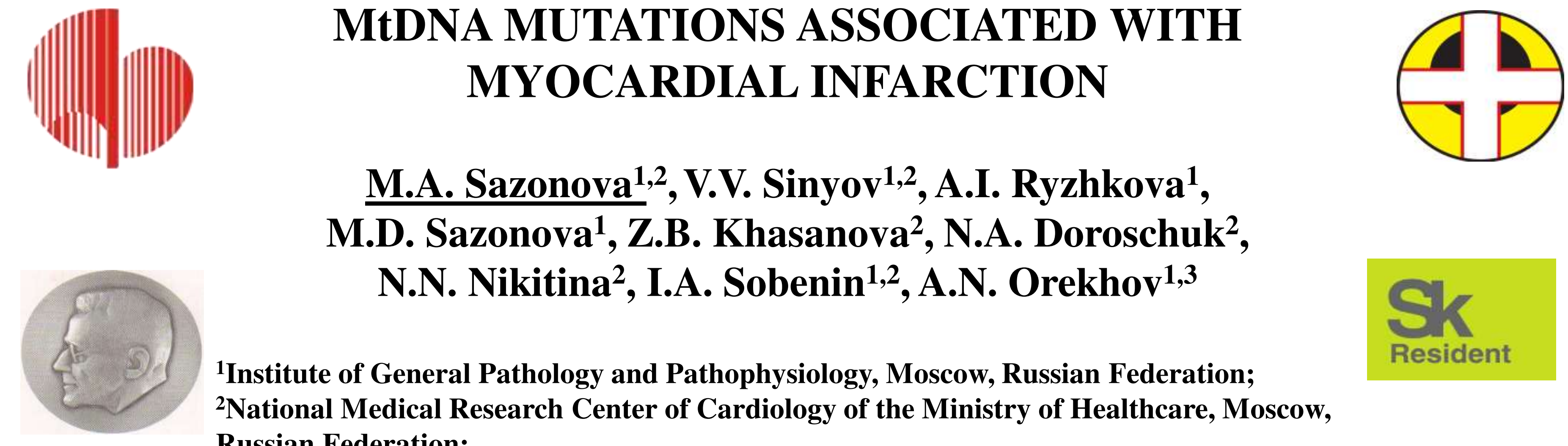

${ }^{2}$ National Medical Research Center of Cardiology of the Ministry of Healthcare, Moscow,

Russian Federation;

${ }^{3}$ Institute for Atherosclerosis Research, Skolkovo Innovative Centre, Moscow Region,

Russian Federation.

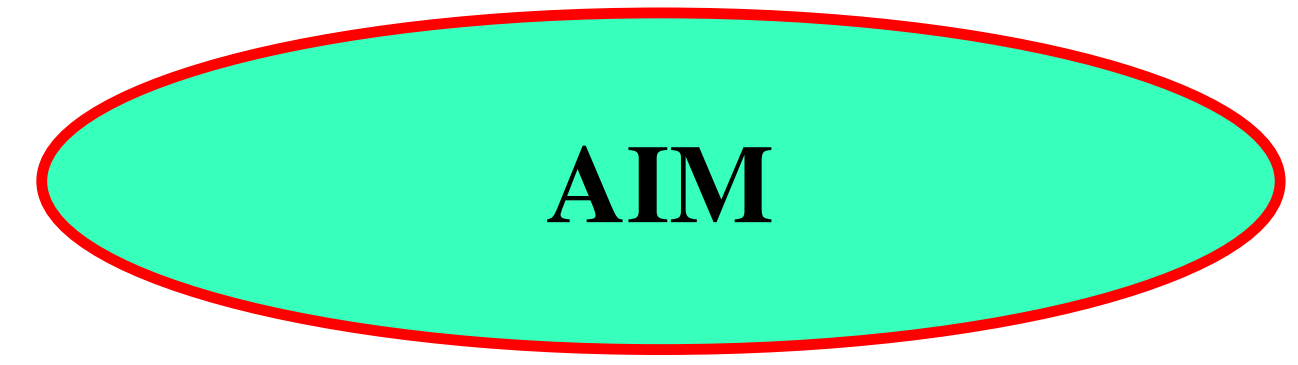

Myocardial infarction is one of clinical manifestations of coronary heart disease. In some cases, the cause of myocardial infarction may be atherosclerotic plaques which occurred in the human aorta. The association of mtDNA mutations with atherosclerotic lesions in human arteries was previously detected by our research group. The aim of the study was to detect mutations mtDNA associated with myocardial infarction.

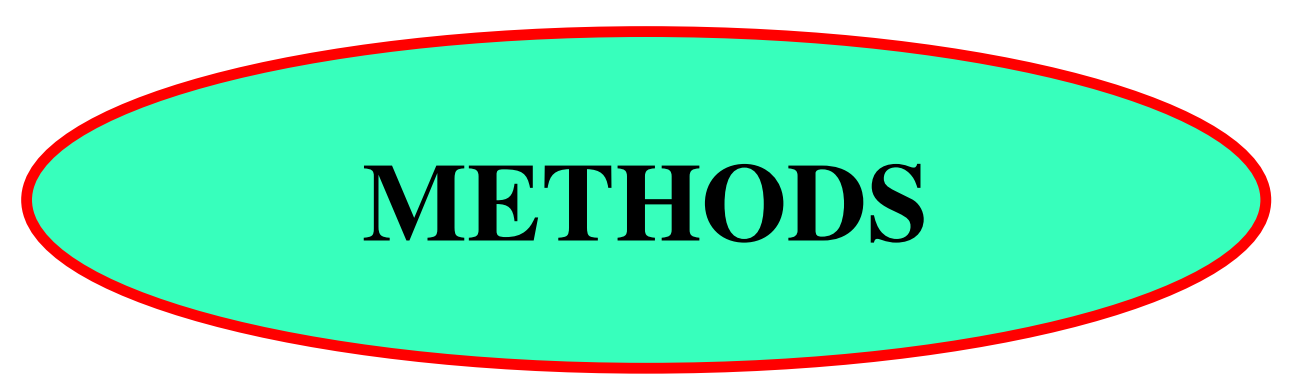

We analyzed samples of white blood cells collected from 225 patients with myocardial infarction and 239 control persons with no health complaints. DNA was isolated from the blood leukocyte samples. Then PCR-fragments of DNA were obtained. They contained the investigated regions of 11 mitochondrial genome mutations $(\mathrm{m} .5178 \mathrm{C}>\mathrm{A}, \quad \mathrm{m} .3336 \mathrm{~T}>\mathrm{C}, \quad 652 \mathrm{delG}$, m.12315G >A, m.14459G $>$ A, 652insG, m.14846G $>$ A, m.1555A $>$ G, m.15059G $>A$, m.3256C $>\mathrm{T}$ ). An estimation of heteroplasmy level percent was carried out by an original method developed in our laboratory, based on pyrosequencing technology. The statistical processing was carried out using IBM SPSS Statistics, version 22.0.

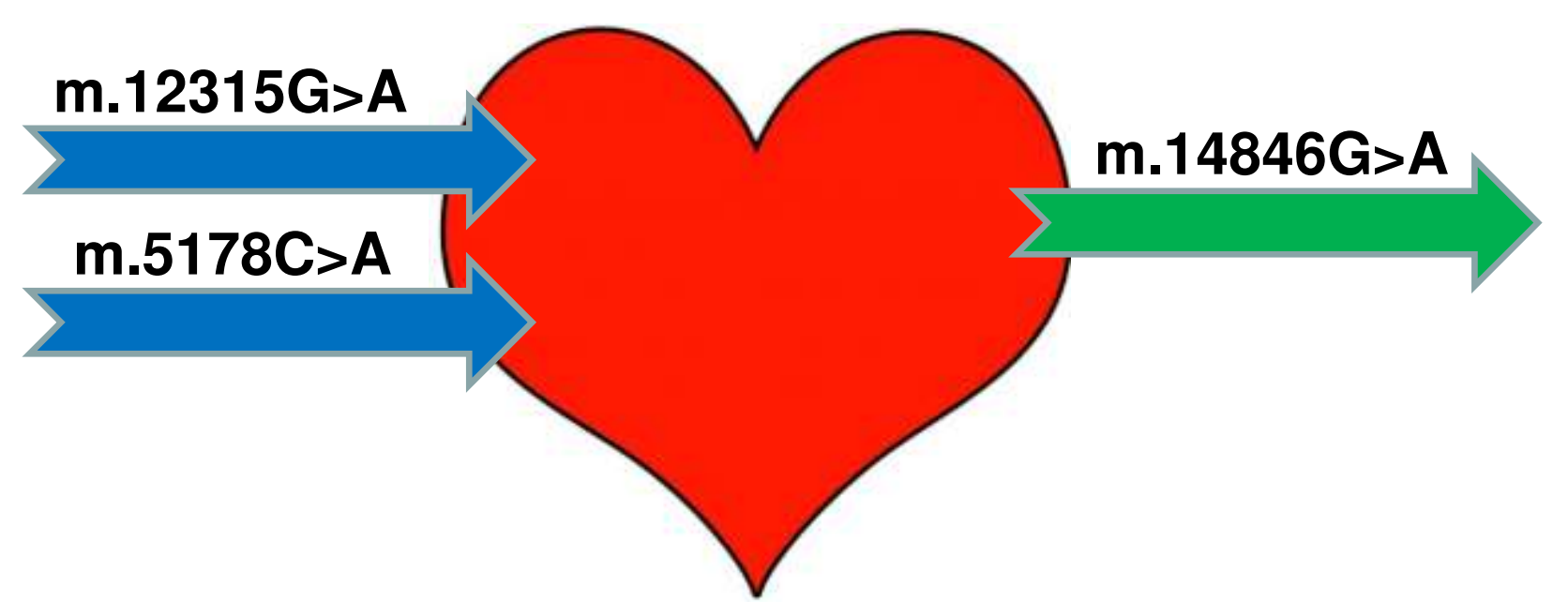

\section{RESULTS}

According to the obtained results, three mutations of human mitochondrial genome correlated with myocardial infarction. A positive correlation was observed for mutation m.5178C >A. At the same time, a highly significant negative correlation with myocardial infarction was observed for mutation m.14846G $>$ A. One single nucleotide substitution of m.12315G $>$ A had a trend for negative correlation.

Spearman correlation of 11 mtDNA mutations with myocardial infarction

\begin{tabular}{|c|c|c|}
\hline Mutation & $\begin{array}{c}\text { Correlation } \\
\text { coefficient }\end{array}$ & Significance \\
\hline m.5178C $>\mathbf{A}$ & 0.109 & $\mathbf{0 . 0 4 5} * *$ \\
\hline m.3336T $>\mathrm{C}$ & 0.051 & 0.198 \\
\hline 652delG & 0.053 & 0.242 \\
\hline m.12315G $>\mathbf{A}$ & -0.096 & $\mathbf{0 . 0 6 5} *$ \\
\hline m.14459G $>\mathrm{A}$ & 0.064 & 0.187 \\
\hline 652insG & -0.045 & 0.229 \\
\hline m.14846G $>\mathrm{A}$ & -0.127 & $\mathbf{0 . 0 0 1} * *$ \\
\hline $\mathrm{m} .1555 \mathrm{~A}>\mathrm{G}$ & -0.059 & 0.191 \\
\hline $\mathrm{m} .15059 \mathrm{G}>\mathrm{A}$ & 0.079 & 0.116 \\
\hline $\mathrm{m} .3256 \mathrm{C}>\mathrm{T}$ & 0.075 & 0.111 \\
\hline
\end{tabular}

Remark: $* *-p \leq 0,05 ; *-p \leq 0,1$.

\section{CONCLUSION}

Mutation m.5178C $>$ A can potentially be useful for creating molecular/cellular models for studying the mechanisms of myocardial infarction. Meanwhile m.14846G $>$ A and m.12315G $>$ A may be useful for developing gene therapy. 